\title{
The Theory of Book Selection
}

Mortimer Taube is head of the Order Department of Duke University Library.

\section{Part I}

$\mathrm{T}$ THE THEORY of book selection is a branch of the general theory of value since it is concerned with problems of choice and discrimination between competing values. Like ethics, aesthetics, or any other branch of value theory, it has two aspects, the descriptive and the normative. The descriptive part of the theory attempts to present a discussion of the bases of choice that are actually operative in practice, of the considerations that determine the selection of this book rather than that. The normative part is concerned with what ought to be the basis of decision in the light of general decisions concerning the objectives of libraries, the purpose of reading, or the aims of education and scholarship.

The first part of this paper will be restricted to a discussion of the descriptive aspect of the theory, with a view of identifying and describing a number of criteria of value employed in book selection. In the second part there will be presented certain reasons why these criteria ought or ought not to be used, and the proper subordination of one criterion to another will also be suggested.

Most librarians who employ these criteria do so without being conscious of them and in the day to day practice of book selection it is proper and fitting that this should be so. We cannot ask a librarian to defer commitment and to state the theoretical grounds for his judgment every time he contemplates making a purchase. Nevertheless, unless he has some realization of what these grounds are, in the long run his policy and practice are apt to be misdirected, confused, and wasteful. It is unfortunately the case that value standards may conflict, that a book which has great value if measured by one criterion may be valueless if measured by another. For a college or university library this possibility of conflicting standards presents a serious problem. In such libraries the responsibility for book selection is divided between the librarian and the diverse groups which make up the faculty. Unless there is reciprocal understanding of the criteria to be employed, results may be disastrous. Moreover, university libraries are composed of many different collections serving many different interests. The proper service of one or another of these interests may require an exclusive regard for one or another of the criteria.

It is possible to distinguish five relatively independent criteria of value that determine policies of book selection, namely, the additive, reference, critical, documentary, and monetary. Since each criterion defines a scale of values, it follows that books have additive, reference, critical, documentary, and monetary value. Any book may have a position on all five 
scales, but its position on any one scale is not determined by its position on any other or by any combination of the others. In mathematical terms, the criteria are independent variables. We may discover empirical correlations between the different values, that is to say, certain books may have high values on each scale or books high on one scale may be low on another; but we cannot deduce the position on one scale from the position on another. In a normative discussion it might be held that some of these criteria ought not to be independent; specifically it might be held that the monetary value should be a function of critical value or that additive value should be a function of documentary value, etc. But since each of these criteria operates independently in the actual practice of book selection, a description of the practice should consider them as independent variables.

\section{Additive Value}

The term "additive" does not represent an altogether happy choice. Webster gives the following definition: "proper to be added . . . capable of being joined so as to cause quantitative increase; involving or characterized by addition." Books, being physical objects, can be added, and libraries publish annual statements of their "quantitative increase." A book has additive value when its addition to a library increases the size of that library.

The relevance of additive value to the practice of book selection is best illustrated by the fact that libraries are ranked by the sizes of their collections. Other criteria may be employed, but I know of no attempt to rule out additive value as a standard for estimating the value of library collections.
There is a sense in which the additive value of all books is equivalent. Adding a book increases the size of the collection, regardless of the nature of the book. But a book may have different additive values for different libraries. In the first place, even though duplicate copies are usually counted in determining the size of a library, the additive value is usually estimated in terms of new titles or books not previously owned by the library. Hence a book will have additive value for one library and not for another.

Secondly, the addition of the same number of titles by several libraries may represent different proportions of increase. Large libraries, in order to maintain numerical superiority and to insure annual increases equal in proportion to the increases of smaller libraries, are forced to subordinate all other criteria to the additive standard. There are some librarians whose chief concern in book selection seems to be to discover titles not already in their libraries. No censure is intended in this statement.

Aside from consideration of size, libraries have another pseudo-quantitative goal for which additive value functions as the criterion of achievement: the attempts to attain complete collections in special subjects. Before a book can have additive value for special collections, it must have a certain imprint, treat a particular topic, be written at a particular time, or be published in a particular place. Once these prior discriminations are made, collectors concern themselves only with additive value. This can be seen in the actual statements of objectives issued by libraries with certain special collections. One collects "all available material relating to Maine ;" another "aims to collect everything printed in America before 
I 820;" a third "aims to assemble everything relating to the literature and history, particularly local history, of Italy since 1870 ;" a fourth "has attempted to secure everything published in the United States on education;" a fifth seeks "all available material relating to the history of the South." Such examples could be listed indefinitely. The fact is that almost every important library in the country is collecting "all" of some specified type of material; and since the specification of type includes no reference to any criterion of value, the unqualified "all" indicates the ubiquity of the additive standard of value.

Every book has some conceivable reference value, but the independent character of this criterion is best illustrated by considering the types of books which function almost exclusively as reference materials, namely, telephone books, directories, Who's Who's, dictionaries, bibliographies, periodical indexes, etc. Such books are (I) intended to be consulted for specific information rather than to be read, and (2) are guides to the use of other materials. The degree to which they serve these purposes determines their reference value and their selection by librarians.

\section{Critical Value}

The obvious character of reference value makes any lengthy discussion of its relevance unnecessary; the same would be true of critical value except that here, as in the discussion of additive value, the lack of an adequate terminology seems to necessitate the use of an ambiguous term. ${ }^{1}$ By "critical value" is meant that type of

1 It is one of the aims of this paper to contribute to the establishment of an adequate terminology. This makes it necessary to point out distinctions and to name what is thus distinguished. No brief is held for the choice of names. value usually intended in judgments that critics, reviewers, or librarians make concerning the average book. In fact, laymen generally suppose, and many librarians share the supposition, that critical value is the only criterion genuinely germane to the concerns of a library. But it is only in relatively small libraries that considerations of critical value are paramount.

In spite of widespread opinions to the contrary, the determination of critical value is not a difficult task. The disagreements of critics concerning the values of books are accorded much more publicity than their importance warrants. In general there is widespread agreement concerning the values of books among competent authorities and it is only in regard to borderline cases that disagreement is apt to occur. There may also be a difference of opinion concerning relative rank.

\section{Selective Lists}

The general agreement concerning critical value has made possible the publication of several lists to which a librarian may refer in selecting books. Such compilations as the Shaw list, the A.L.A. Catalog, the Sonnenschein list, etc., are not presented as products of subjective choice but as the results of a critical consensus. Hence the librarian who is reasonably well informed will have little difficulty utilizing the criterion of critical value.

It was observed above that the questions of critical value seem to be of importance primarily in small libraries. This statement must now be qualified. Books of high critical value are of major importance to all libraries, but their small number relative to the existing volume 
of publications makes it possible for large libraries to possess or buy all of them and the librarian is not confronted with the necessity of choice. No college or university library of average size is forced to choose between Milton or Shakespeare, Tolstoi or Dostoevsky, Dickens or Scott, Frost or Jeffries. And every first class college or university library has an annual budget appropriation sufficient to purchase the new books of outstanding critical value in fields represented in its curriculum. Many will object to this observation. It is sufficient to remark that librarians will sometimes spend for a rare imprint or first edition enough money to buy the complete works of a dozen major English poets.

\section{Documentary Value}

The exhibits of a great art museum or the repertoire of a great concert orchestra reflect the taste and judgment of generations of critics, but the shelves of a great research library do not reflect a parallel discrimination. Some of our research libraries seem to collect the bad book, the cheap novel, the pompous genealogy, the insipid poem, the lying history, the dull report, the stupid diary, the ephemeral tract, etc., just as they collect the works of established critical value. It must be that in flaunting the decisions of the critics and the accumulated judgment of thousands of readers, the research library is appealing to some other standard of values. This is indeed the case; the research library serves the scholar who may be primarily concerned with documentary value. $^{2}$

\footnotetext{
2 In Europe there is a general appreciation of the distinction between books of critical and cultural value and documents "collected for purposes of evidence, verification, or study," although there is no agreement as to whether the collection of documentary material is a function of libraries or a task
}

Any type of printed matter or manuscript has documentary value if it can conceivably be used by the literary, political, or social historian. The historian uses these materials as the anthropologist or archeologist uses artifacts, namely, to gain an understanding of the past that shall be as complete as possible. Considered as historical evidence, the trashiest novel may be as significant as a literary masterpiece. And this fact has given rise to the paradox of book selection. The books of critical value of any historical era will, in general, be reasonable in price and common; but the dime novel or the penny broadside will be expensive and rare. Hence, a librarian of a research institution may be asked to devote an undue proportion of his funds and energy to the purchase of material with documentary value but of no critical value.

The question must arise as to whether there is any limitation which applies to the class of materials . which have documentary value. It is generally assumed that everything has such value and if this is so, it follows that additive and documentary value tend to coincide.

It may be objected that the two criteria are distinguished by the fact that the additive value of all books is identical, whereas the documentary values of books may vary. Unfortunately, current practice gives us no satisfactory indication of how relative documentary value is to be determined. The documentary value of any type of material may rise or fall with the changing fashions and problems of scholarship and may vary in different institutions and

for separate institutions. In America the term "document" is usually restricted to publications of government agencies. As used herein, this restric-

tion does not apply. and Documentation" by Marcel Godet in the Library Quarterly 9:185.92, Apr. 1939. 
regions depending upon the interests of local scholars. Most librarians feel quite justly that they cannot build balanced collections upon the shifting sands of current interest. But lacking any criterion that can measure the significance of scholars' interests or any foreknowledge of what may interest the next generation of scholars, libraries with sufficient funds tend to identify documentary and additive value. Libraries that cannot afford this identification must play a guessing game and bury their bad guesses in the stacks. It is a fair judgment that about half of the books in the Library of Congress will never be used from now to the end of time, but no scholar or librarian, or even a committee composed of many scholars and librarians, would venture to decide "which half."

\section{Monetary Value}

If it were possible to consider all the reasons and considerations which determine the book selections of libraries it would not be necessary to treat monetary value as an independent variable. Monetary value would become a function of all other values and would be determined by the critical value, the scholarly value, etc. However, the considerations which determine book selection are unlimited. The four criteria already discussed are the most significant but many more could be presented. Libraries value books because they were published before a certain date, because they were written by local authors, because they are bound in certain ways and are printed with a certain type font, because they were once possessed by famous men, because they are numbered copies, because they are autographed, because they are first editions, because they are fake first editions, because they are scarce, etc. It should be apparent that it is hopeless to attempt to discuss all the minor criteria of value used by libraries. Rather, I have chosen to regard monetary value as their common denominator. All of them taken together determine the price of books (other than trade books) to a greater extent than do any of the criteria that have been discussed. Hence, so far as these four criteria are concerned, monetary value is an independent variable. If anyone wishes to attempt an exhaustive account of the reasons why books are considered valuable, I wish him joy in the venture and promise to deny the independence of monetary value as soon as he announces his success. ${ }^{3}$

(To be continued) 3 It is acceptable scientific practice to treat a
variable as independent so long as it is impossible
to specify the conditions upon which it depends,
even if there is reason to believe in the existence of such conditions. 